\title{
To Analyze Variables Considered as Potential Risk Factors for Gastro Intestinal Anastomotic Leaks
}

\author{
Achal Agrawal ${ }^{1}$, Abhineet Kumar Jain ${ }^{2}$ \\ ${ }^{1}$ Consultant, Department of Surgery, Laparoscopic GI and Bariatric Surgeon and Greater Kailash Hospital, Indore, ${ }^{2}$ Senior \\ Resident, Department of Surgery, Gandhi Medical College, Bhopal, India
}

Corresponding author: Dr. Abhineet Kumar Jain, Senior Resident, Department of Surgery, Gandhi Medical College, Bhopal, India

DOI: http://dx.doi.org/10.21276/ijcmsr.2018.3.4.20

How to cite this article: Achal Agrawal, Abhineet Kumar Jain. To analyze variables considered as potential risk factors for gastro intestinal anastomotic leaks. International Journal of Contemporary Medicine Surgery and Radiology. 2018;3(4):D87-D89.

\section{A B S T R A C T}

Introduction: The study conducted in the department of surgery, consent from the patient was taken to proceed the cases development with gastrointestinal anastomotic leaks, admitted and managed in Hospital were evaluated by using prestructured Pre-Tested proforma. Study aimed to analyze variables considered as Potential Risk factors for Gastro Intestinal Anastomotic leaks.

Material and Methods: This Prospective Longitudinal Study was conducted in the department of surgery, consent from the patient was taken to proceed the cases development with gastrointestinal anastomotic leaks, admitted and managed in Hospital and were evaluated by using pre-structured Pre-Tested proforma.

Result: The most common risk factor for AL identified in this study was Hypoalbuminemia $(n=24,80 \%)$ followed by blood loss ( $n=11,36.66 \%)$, intraop-contamination $(n=8,26.66 \%)$, Chronic smoking $(n=6,20 \%)$. Other factors identified were Comorbidities $(n=5,16.66)$ such as COPD, TB, CAD, DM $(n=4,13.33 \%)$, Chemotherapy $(n=4,13.33 \%)$, Duration of Surgery $>200$ $\min (n=4,13.33)$ History of RT $(n=2,6.66 \%)$.

Conclusion: Anastomotic leak is one of the most pertinent complications following GI surgery. Consequently, it is the obligation of surgeons to do their best to reduce the risk of Anastomotic leaks. In spite of one's best efforts, these complications are bound to occur and we cannot underestimate the importance of a high index of suspicion leading to early diagnoses of leaks.

Keywords: Potential Risk, Gastro Intestinal, Anastomotic Leak

\section{INTRODUCTION}

Intestinal anastomosis dates back to 1000 B.C., the era of Sushruta "The Great Indian Surgeon" where he described the use of black ants for intestinal anastomosis. ${ }^{1}$ Intestinal anastomosis has been effectively performed for more than 150 years using a assortment of techniques, materials and devices.

Intestinal obstruction, peritonitis secondary to perforated bowel and abdominal trauma, are common surgical problems encountered throughout the world. These problems usually require to be treated operatively. Intestinal anastomosis is an important procedure in general surgery in which bowel must be accurately approximated without tension while retaining blood supply to both ends. ${ }^{2}$

Healing of the intestinal tract is rapid when free of complications. Unlike cutaneous wound healing progress cannot be observed on a daily basis and intervention instituted early if necessary. Healing of the intestinal anastomosis cannot be anatomically observed from inspection, allowing the surgeon only to judge the success of operation by assessing the patient's parameters of general well being. For the same reason, complications usually warrant re-exploration, with associated morbidity and mortality. ${ }^{3}$

The essential rules for a reliable anastomosis is to ensuring a good exposure through a suitable incision, sufficient blood flow of the anastomosis, the absence of tension, minimization of septic time by means of colon preparation. Study aimed to analyze variables considered as Potential Risk factors for Gastro Intestinal Anastomotic leaks.

\section{MATERIAL AND METHOD}

All patients who presented with, or developed gastrointestinal anastomotic leak at Greater Kailash Hospital, Indore between period of July 2016 to December 2017 and the study was carried out till the required sample size of thirty cases was fulfilled.

Sample size: 30 cases.

\section{Inclusion Criteria}

1. All patients developing anastomotic leaks following Gastrointestinal surgery.

2. All postoperative fistulas communicating with the surgical anastomosis. 


\section{Exclusion Criteria:}

1. Patients who were transferred from hospitals with a leak, abscess or fistula.

2. Moribund patients.

3. Patients below age of 18 years.

4. Patient who declined to give consent.

\section{Methodology}

The principal investigator recorded demographic details of each patient developing AL, indications for operation, operation performed and technique, assessment for potential risk factors for $\mathrm{AL}$ and outcome parameters such as duration of hospital stay and mortality.

Clinical anastomotic failure was considered when patient developed postoperative peritonitis (local or generalized), established fecal fistula, or intra-abdominal abscess with communication with bowel (on contrast studies) or if leak was apparent at re-exploration. Contrast studies were not used routinely but was performed selectively to document clinical suspicion of anastomotic failure in various anastomosis or to localize the fistula in cases of failed conservative management. Intra-peritoneal abscess means clinical presentation with ultrasonic evidence of intraperitoneal collection of pus. Patients were followed up for 3 months after the date of discharge.

\section{RESULTS}

Table 1 shows the most common site for AL was the ileum (63.33\%), followed by ileocolonic (10\%) and colo-colonic (10\%) leak. Jejunal (6.66\%) anastomic leak was found in 2 cases. Only a single case of Gastrojejunostomy developed AL. The commonest anastomotic technique used was found to be single layer continuous suturing technique which was performed in $20(66.66 \%)$ cases.

\begin{tabular}{|l|c|c|}
\hline Anastomotic Category & Number & Percentage \\
\hline Ileo-ileal & 19 & 63.33 \\
\hline Ileo-colonic & 3 & 10 \\
\hline Jejuno-Jejunal & 2 & 6.66 \\
\hline Gastro-Jejunal & 1 & 3.33 \\
\hline Colo-Colonic & 3 & 10 \\
\hline Hepatico -Jejunal & 2 & 6.66 \\
\hline Total & 30 & 100 \\
\hline
\end{tabular}

Table-1: Distribution of Cases according to Anastomotic Category

\begin{tabular}{|l|c|c|}
\hline Risk Factor & Number & Percentage \\
\hline Anemia(Hb<10) & 4 & 13.33 \\
\hline Hypoalbuminemia (Sr. Albumin<3.2) & 24 & 80 \\
\hline Diabetes Mellitus & 4 & 13.33 \\
\hline Chronic Smoker & 6 & 20 \\
\hline Chemotherapy & 4 & 13.33 \\
\hline History of RT & 2 & 6.66 \\
\hline Co-morbidities & 5 & 16.66 \\
\hline Blood loss >200 ml & 11 & 36.66 \\
\hline Surgery Duration>200 min & 4 & 13.33 \\
\hline Intra-op Contamination & 8 & 26.66 \\
\hline Table-2: Prevalence of Established Risk Factors among cases \\
\hline
\end{tabular}

Table 2 shows the most common risk factor for AL identified in this study was Hypoalbuminemia $(n=24,80 \%)$ followed by blood loss ( $n=11,36.66 \%)$, intraop-contamination $(n=8,26.66 \%)$, Chronic smoking $(n=6,20 \%)$. Other factors identified were Co-morbidities $(n=5,16.66)$ such as COPD, TB, CAD, DM ( $n=4,13.33 \%)$, Chemotherapy ( $n=4,13.33 \%)$, Duration of Surgery $>200$ min $(n=4,13.33)$ History of RT $(n=2,6.66 \%)$.

\section{DISCUSSION}

The unsophisticated healing of an intestinal anastomosis even after considerate technical performance from an experienced surgeon is still a challenge because the healing process is dependent on multiple physiological, biochemical, and morphological factors.

In this study we evaluated anastomotic leak following gastrointestinal in surgery department with detailed analysis of patients was done on the day of diagnosis of leak and they were observed till the date of discharge or death. Patients who were discharged were followed for a period of 3 months. We identified definitive risk factors for AL and their prevalence among cases.

Risk factors for anastomotic leak have traditionally been stratified into 2 categories: Pre-operative/patient related factors and operative factors

\section{Pre-operative/patient related factors \\ Gender and Age}

In our study, $73 \%$ of cases were male and majority of them were more than 50 years of age. Some studies have demonstrated that increasing age or age $>60$ is associated with an increased risk of AL. ${ }^{4} \mathrm{AL}$ has been linked inversely with increasing age. ${ }^{5,6}$ This connection may be secondary to a number of factors, including the presence of co morbid conditions such as cardiac, renal, liver disease, malnutrition, and vitamin deficiency. ${ }^{7}$

\section{Management}

In our study, of the 30 cases of AL, majority of cases were re-operated(73.33\%). While conservative management was done in 8 cases (26.66\%). The most common surgical intervention was found to be creating a Defunctioning stoma. Revision of anastomosis was done in 3 cases(10\%) of AL. Conservative management was attempted in 2 cases who had developed low output ECF and haemodynamically stable. While 6 cases had complicated into either Septic shock, peritonitis, MODS, Renal failure making them poor candidates for re-exploration.

Consequent management requires a thorough assessment of the patient's clinical stability. A stable patient may initially be sufficiently managed conservatively, with fluids, antibiotics and oxygen, together with close clinical observation. On the contrary, an urgent attempt to achieve source control must be undertaken in any patient with an $\mathrm{AL}$ and severe sepsis or septic shock, within the time frame.

A patient with an $\mathrm{AL}$ must be nursed in an environment suitable to their level of systemic illness and the consequent need for monitoring. Recommended time limits for intervention in the treatment of abdominal sepsis associated with AL have been identified previously, and are determined 
by the severity of sepsis. ${ }^{8}$ In the absence of organ dysfunction, surgical or radiological intervention to achieve source control should be undertaken as soon as possible but always within 18 hours of diagnosis. If sepsis is complicated by proof of organ dysfunction, source control must be attained as soon as possible, but always within 6 hours of diagnosis. Septic shock should result in source control immediately and always within 3 hours, if death is to be avoided. ${ }^{9,10}$

\section{CONCLUSION}

Anastomotic leak is one of the most pertinent complications following GI surgery. Consequently, it is the obligation of surgeons to do their best to reduce the risk of Anastomotic leaks. In spite of one's best efforts, these complications are bound to occur and we cannot underestimate the importance of a high index of suspicion leading to early diagnoses of leaks.

\section{REFERENCES}

1. Singh RK, Vyas MK. Surgical procedures in Sushruta Samhita. International Journal of Research in Ayurveda and Pharmacy 2011; 2(5):1444 - 1450.

2. Morris AM, Baldwin LM, Matthews B, Dominitz JA, Barlow WE, Dobie SA, Billingsley KG. Reoperation as a quality indicator in colorectal surgery: a populationbased analysis. Ann Surg. 2007;245(1):73-79.

3. Jung SH, Yu CS, Choi PW, Kim DD, Park IJ, Kim $\mathrm{HC}$, Kim JC. Risk factors and oncologic impact of anastomotic leakage after rectal cancer surgery. Diseases of the colon and rectum 2008;51(6): 902-908.

4. Damhuis RA, Wereldsma JC, Wiggers T. The influence of age on resection rates and postoperative mortality in 6457 patients with colorectal cancer. International journal of colorectal disease 1996;11(1): 45-48.

5. Khoury GA, Waxman BP. Large bowel anastomosis: I. The healing process and sutured anastomoses: a review. Br J Surg 198370:61.

6. Schrock TR, Deveney CW, and Dunphy JE: Factors contributing to leakage of colonic anastomoses. Ann Surg 1973;177(3):513.

7. Barone JE. Abnormal vital signs not a good indicator of anastomotic leaks. Medscape Medical News. March 24, 2014.

8. The Higher Risk General Surgical Patient Towards Improved Care for a Forgotten Group.https:// www.rcseng.ac.uk/publications/docs/higher-ris surgicalpatient/ .

9. Fouda E, El Nakeeb A, Magdy A, Hammad EA, Othman G, Farid M. Early detection of anastomotic leakage after elective low anterior Resection. J Gastrointest Surg. 2011;15(5):137-144.

10. Garude K, Tandel C, Rao S, Shah NJ. Single layered intestinal anastomosis: a safe and economic technique. Indian J Surg. 2013;75(4):290-3.

Source of Support: Nil; Conflict of Interest: None

Submitted: 12-10-2018; Accepted: 13-11-2018; Published online: 07-12-2018 